\title{
Experimental Study on the Fire Spreading between Vehicles Using a Real Scale Fire Test
}

\author{
Dabin Baek, Young Gi Park, Hong Sun Ryou \\ Department of Mechanical Engineering, Chung-ang University \\ 84, Heukseok-Ro, Dongjak-Gu, Seoul, 156-756, South Korea \\ baekda@cau.ac.kr; pyg0511@naver.kr; cfdmec@cau.ac.kr
}

\section{Extended Abstract}

With increasing vehicle, the vehicle fire is considered one of the dangerous disaster. Because vehicles have the many inflammable materials as like gasoline engine oil, plastic and leather etc. Especially, when the vehicle fire is occurred in underground parking lot, the fire can easily spread around the vehicles due to the narrow parking space. [1] Thus, the vehicle fire can be developed to the large fire. In order to prevent the fire spreading, the fire extinguishing systems are installed in underground parking lot. However, these extinguishing systems are designed initial fire suppression, thus it is difficult to extinguish the large fire due to the fire spreading. [2] Therefore, fire spread between vehicles should be considered to improve extinguishing performance. In this study, experimental studies are performed to analyse the fire spread characteristics between vehicles using a real scale fire tests. The fire spread characteristics is analysed by using the temperature measured in various part of the vehicle.

The fire is occurred at passenger seat by using the gasoline. Also, the vehicles used in the experiments are the fourwheel sedan. The vehicle is divided into four regions according to the characteristics of the inflammable materials (seat, engine room, fuel tank and bumper) [3]. Also 10 to $16 \mathrm{~K}$-type thermocouples (chromel-alumel, temperature range: -200 $1260 \mathrm{oC}$ ) are installed in each regions.16 thermocouples installed inside the passenger are consisted of driver seat region, passenger seat region, back seat region. Also four thermocouples are installed in for each sheet with the interval $0.2 \mathrm{~m}$. Engine room and oil tank region are consisted of upper surface, lower surface and side surface. Thermocouples installed in upper surface and lower surface are located on the corner of engine room. Also 8 thermocouple are installed in side surface is located in center by two each side. The bumper region is consisted of front bumper and back bumper. Also five thermocouple are installed in for each bumper with the interval $0.3 \mathrm{~m}$. Every thermocouples are connected to the indicator (Agilent 34970A), and the temperature data from the indicator are transmitted to the PC by RS-232 cable. Moreover, the Heat release rate is measured by using the large cone calorimeter. As a results of experiments, the fire was spread through radiant heat transfer. Especially, the temperature distribution on the vehicles is analysing by using the thermocouples. The fire is spread in order of seat (600 s), engine room (900 s), fuel tank (1340 s), and bumper (1470 s). Also, Maximum heat release rate is $6 \mathrm{MW}$ at $1600 \mathrm{~s}$. From this result, the fire spreading between vehicles and heat release rate are confirmed. Finally, this results will be used as basic data about the vehicle fire spread in numerical analysis

\section{Acknowledgement}

This research was supported by the Fire Fighting Safety \& 119 Rescue Technology Research and Development Program funded by the Ministry of Public Safety and Security ("MPSS-Fire Fiting-2015-80") and the Korea Institute for Advancement of Technology (KIAT) grant funded by the Korea Government - Ministry of Trade Industry and Energy (MOTIE). (No. N0001075).

\section{References}

[1] K. Seunggu, "Vehicle fire," M. S. dissertation, Dept. Mechanical Engineering, HOSEO University.

[2] K. Y. Tak, "Thermal Characteristics of Car Interior Materials Using Cone Calorimeter," in Proceeding of the Korea Institute of fire science \& engineering, Korea, vol. 1, pp. 557-563, 2009. 
[3] P. E. Young, "Combustion Characteristics of Car Components Using Cone-Calorimeter," Journal of Korean Society for Atmospheric, vol. 25, no. 3, pp. 237-247, 2009. 